\title{
Preflaring effects on the accuracy of three electronic apex locators
}

\section{Efeitos do pré-alargamento na acurácia de três localizadores apicais eletrônicos}

\begin{abstract}
Purpose: To compare the accuracy of three electronic apex locators (EALs) and evaluate the influence of cervical preflaring in them.

Methods: The working length (WL) of thirty extracted human mandibular incisors was determined visually. All teeth were mounted in conducting medium and tested with: Novapex, Mini Apex Locator and Propex II. The electronic WL was determined before and after preflaring with LA Axxess burs. Differences between the electronic and visual WL were calculated and analyzed by Friedman and Wilcoxon tests. Radiographs were taken using the electronic WL of each EAL and the distance between the instrument tip and the radiographic apical vertex was measured. This value was compared to a reference or ideal value $(1 \mathrm{~mm})$ by one-sample $t$ test.

Results: The Novapex was the most accurate EAL before and after the preflaring procedure, which was confirmed by the radiographic analysis. All EALs tested increased their accuracy after preflaring, but no significant difference was noted for the Novapex.

Conclusion: The Novapex was more accurate compared to the Mini Apex and Propex II. Preflaring procedure was advantageous for all EALs.
\end{abstract}

Key words: Endodontics; root canal preparation; tooth apex

\section{Resumo}

Objetivo: Comparar três localizadores apicais eletrônicos (LAEs) e avaliar a influência do pré-alargamento cervical na sua acurácia.

Métodos: O comprimento de trabalho (CT) de trinta incisivos inferiores humanos extraídos foi determinado visualmente. Todos os dentes foram montados em um meio condutor e testados com Novapex, Mini Apex Locator e Propex II. O CT eletrônico foi determinado antes e após pré-alargamento com brocas LA Axxess. As diferenças entre o CT eletrônico e visual foram calculadas e analisadas pelos testes de Friedman e Wilcoxon. Radiografias foram realizadas com o CT eletrônico de cada LAE e a distância da ponta do instrumento ao vértice radiográfico foi mensurada. Este valor foi comparado com um valor de referência ou ideal (1 mm) pelo teste † para uma amostra.

Resultados: Novapex foi o LAE mais preciso antes e após procedimento de pré-alargamento, o que foi confirmado pela análise radiográfica. Todos os LAEs testados aumentaram sua acurácia após pré-alargamento, mas não foi observada diferença significativa para o Novapex.

Conclusão: Novapex foi mais preciso que Mini Apex e Propex II. O procedimento de préalargamento foi vantajoso para todos os LAEs.

Palavras-chave: Endodontia; preparo do canal radicular; ápice dental

\author{
Renata Dornelles Morgental a \\ Fabiana Vieira Vier-Pelisser ${ }^{\circ}$ \\ Simone Bonato Luisi b \\ Deborah Meirelles Cogoa \\ Patrícia Maria Poli Kopper b
}

\begin{abstract}
- School of Dentistry, Pontifical Catholic University of Rio Grande do Sul (PUCRS), Porto Alegre, RS, Brazil

bSchool of Dentistry, Federal University of Rio Grande do Sul (UFRGS), Porto Alegre, RS, Brazil
\end{abstract}

Correspondence:
Renata Dornelles Morgental
Avenida Itaqui, 71/201
Porto Alegre, RS - Brazil
$90460-140$
E-mail: remorgental@hotmail.com

Received: October 9, 2011

Accepted: December 13, 2011

Conflict of Interests: The authors state that there are no financial and personal conflicts of interest that could have inappropriately influenced their work.

Copyright: (c) 2011 Morgental et al.; licensee EDIPUCRS. This is an Open Access article distributed under the terms of the Creative Commons AttributionNoncommercial-No Derivative Works 3.0 Unported License. 


\section{Introduction}

The correct determination of the working length (WL) is an important step in endodontic treatment and it prevents potential aggression to the periapical region (1). The apical constriction marks the transition between the pulpal and periodontal tissue, so it should be the ideal point to end the root canal instrumentation and obturation (2). This anatomic landmark might be located at $0.5-1 \mathrm{~mm}$ from the apical foramen (3).

Methods of WL establishment include tactile sense, radiographs, and electronic apex locators (EALs). The first method is highly variable and its accuracy is questionable (4). Radiographic measurements are widely used, but this method is influenced by vertical and horizontal cone angulations, film processing procedures, and tooth inclination (5). Moreover, the superimposition of bony structures such as zygomatic arch could impair the identification of the radiographic apex of some teeth (6).

Sunada (7) idealized the first electronic device employed in WL establishment. At that time, there were limitations related to the presence of pulp tissue and moisture inside the root canal. The EALs evolved and currently they work based on the difference of impedance, calculated with two or more frequency signals (1). Some studies have shown that the EALs were more accurate than radiographs in determining the WL (8). These devices are also able to detect root fractures and perforations $(9,10)$.

According to ElAyouti et al. (11), several factors can influence the electronic measurements, such as: apical constriction diameter, instrument size and the irrigating solution used during the procedure. Furthermore, some researchers suggested better accuracy with the use of EALs when the root canals were preflared before instrumentation $(12,13)$.

Nowadays, there is a wide variety of EALs on the market. The Novapex (Forum Tec, Rishon Le-zion, Israel) is a low cost device. Its reliability in detecting the apical foramen was $82.1 \%$, considering the tolerance of $\pm 0.5 \mathrm{~mm}$ (14). This EAL showed a no-function rate of $15 \%$ at an in vivo study, especially in retreatment cases (15).

Another EAL, the Mini Apex Locator (SybronEndo, Sybron Dental, Anaheim, CA) is a multi-frequency-based device. Some studies have verified its satisfactory capability in determining the WL $(12,16)$, with similar values, presented by Root ZX and Root ZX II (J Morita Corp).

Recently, a new multi-frequency-based EAL became available, the ProPex II (Dentsply-Maillefer, Ballaigues, Switzerland). Its accuracy ranged from $83.45 \%$ to $91.41 \%$ with different instrument sizes and the tolerance of \pm 0.5 $\mathrm{mm}$ (17). An ex vivo study verified that the ProPex II was more accurate in determining the WL than Root $\mathrm{ZX}$ and than digital radiography (18).

However, in the quoted investigations, the electronic measurements were made after coronal preflaring and it was not possible to say if this procedure would interfere in the results. Then, the aim of this in vitro study was to compare the accuracy of three EALs and to evaluate the influence of preflaring in their accuracy.

\section{Methods}

The present study was approved by the Research Ethics Committee of the Pontifical Catholic University of Rio Grande do Sul (SISNEP number 0149.0.002.165-11).

\section{Sample}

Thirty human mandibular incisors were used in this study. The teeth were radiographed in both mesiodistal and buccolingual views to verify the absence of calcification, root resorption or canal curvatures. After coronal access, debris and remnants of pulp tissue were removed with a size 10 K-file (Dentsply-Maillefer, Ballaigues, Switzerland). The root canals were irrigated by using $1 \%$ sodium hypochlorite solution $(\mathrm{NaOCl})$ with a 30 -gauge needle and a $5 \mathrm{~mL}$ syringe (Ultradent, South Jordan, UT).

\section{WL determination by visual method}

The study design used was adapted from Camargo et al. (12). In order to provide a regular reference level, the incisal edges of the teeth were flatened by using a carborundum disc (Schelble, Petrópolis, Brazil). A size 10 K-file with a silicon stop was introduced into the root canal until its tip was seen at the level of the apical foramen. This procedure was performed with the aid of magnifying glasses (4.0X magnification).

Once the file tip was observed at the apical foramen, the silicon stop was stabilized at the incisal edge. The file was removed, and the distance between the silicon stop and the file tip was measured with a $0.5 \mathrm{~mm}$ precision ruler $(\mathrm{ARCH}$, Tokyo, Japan). This measure was defined as the total length of the root canal. The visual WL was established by reducing $1 \mathrm{~mm}$ from the total length and recorded.

\section{WL determination by electronic methods}

For electronic measurements, each tooth was immersed in a plastic recipient containing fresh alginate (Alga Gel; Technew, Rio de Janeiro, Brazil). Two orifices were made, one in the center for placing the tooth and the other laterally for placing the lip electrode of the EALs. Three devices were evaluated: Novapex, Mini Apex Locator and ProPex II. The root canals were previously irrigated with $1 \% \mathrm{NaOCl}$ and cotton pellets were used to remove excess from the pulp chamber. Then the lip electrode was immersed in the respective orifice in the conductive medium. A K-file adjusted to the canal walls was connected to the other electrode.

For each procedure, a file was slowly inserted into the root canal until the "OVER" or "PAST APEX" signal was seen on the LED or display screen, and then gently retracted to the "ZERO" or "APEX" signal. Following, a silicon stop was carefully adjusted to this reference level, and the distance between the silicon stop and the file tip was measured with a ruler. The electronic WL was established by reducing $1 \mathrm{~mm}$ from this measurement and recorded. 


\section{Preflaring procedure}

After electronic measurements with each EAL, all root canals were preflared by using a LA Axxess 20/.06 bur (SybronEndo, Sybron Dental, Anaheim, CA) in a low speed handpiece (Kavo, Joinville, Brazil). The bur was introduced into the root canal with a continuous movement, until resistance was found. New irrigation was performed with $1 \% \mathrm{NaOCl}$. All root canals were electronically measured once again and the electronic WL were recorded.

The electronic measurements were performed in triplicate for each tooth before and after preflaring. The mean values were calculated.

\section{Radiographic measurements}

Standardized radiographs in buccolingual view were taken using a K-file calibrated at the mean electronic WL of each EAL after preflaring. The distance between the instrument tip and the radiographic apical vertex was measured with a ruler and recorded.

\section{Statistical analysis}

The mean differences between the electronic and visual WL were calculated for each EAL before and after preflaring. Data were submitted to Friedman test and multiple comparison procedure in both situations. Then, the differences before and after preflaring were compared by Wilcoxon test. The proportion of measurements within $\mathrm{a} \pm 0.5 \mathrm{~mm}$ range of clinical acceptability was calculated for each EAL before and after preflaring. For radiographic measurements, comparison between the value obtained for each EAL after preflaring and the reference or ideal value (1 mm) was performed using one-sample t test. This reference was the ideal value expected since the apical limit for root canal instrumentation and filling should be $1 \mathrm{~mm}$ short from the radiographic apical vertex. The level of significance was established at 5\%. Statistical analysis was performed with the software SPSS (SPSS Inc, Chicago, IL).

\section{Results}

Before the preflaring procedure, the mean differences between electronic and visual WL were $-0.06 \mathrm{~mm} ;-0.29$ $\mathrm{mm}$ and $-0.36 \mathrm{~mm}$ for the Novapex, Mini Apex and Propex II, respectively. Significant difference was noted between the Novapex and Mini Apex and between the Novapex and Propex II $(P<0.05)$. After preflaring, the mean differences were $-0.03 \mathrm{~mm} ;-0.13 \mathrm{~mm}$ and $-0.23 \mathrm{~mm}$ for the Novapex, Mini Apex and Propex II, respectively. Significant difference was detected between all EALs $(P>0.05)$, as shown in Table 1 .

The electronic WL was closer to the visual WL after preflaring for all EALs (Table 1). But while for Mini Apex and Propex II there was a significant difference between the measurements before and after preflaring $(P<0.05)$, this did not happen for the Novapex $(P>0.05)$.

The proportions of measurements within $\mathrm{a} \pm 0.5 \mathrm{~mm}$ range of clinical acceptability were demonstrated in Table 2. All the EALs tested presented high percentage of acceptable cases before preflaring and even higher after this procedure.

Table 1. Mean differences $(\mathrm{mm})$ between electronic and visual length before and after preflaring

\begin{tabular}{lccc}
\hline \multicolumn{1}{c}{ Group } & $\begin{array}{c}\text { Novapex } \\
\mathrm{n}=30\end{array}$ & $\begin{array}{c}\text { Mini Apex } \\
\mathrm{n}=30\end{array}$ & $\begin{array}{c}\text { Propex II } \\
\mathbf{n}=30\end{array}$ \\
\hline Before preflaring & $-0.06 \pm 0.31^{\mathrm{a}, \mathrm{A}}$ & $-0.29 \pm 0.32^{\mathrm{b}, \mathrm{B}}$ & $-0.36 \pm 0.31^{\mathrm{b}, \mathrm{D}}$ \\
After preflaring & $-0.03 \pm 0.15^{\mathrm{c}, \mathrm{A}}$ & $-0.13 \pm 0.18^{\mathrm{d}, \mathrm{C}}$ & $-0.23 \pm 0.26^{\mathrm{e}, \mathrm{E}}$ \\
\hline
\end{tabular}

Negative values indicate means shorter than the visual canal length.

Different small letters, in the same line, indicate significant difference between the EALs.

Different capital letters, in the same column, indicate significant difference before and after preflaring, considering each EAL.

Table 2. Proportion of measurements within a $\pm 0.5 \mathrm{~mm}$ range of clinical acceptability

\begin{tabular}{llcccc}
\hline \multirow{2}{*}{ Group } & \multicolumn{1}{c}{ Result } & \multicolumn{2}{c}{ Before preflaring } & \multicolumn{2}{c}{ After preflaring } \\
\cline { 3 - 6 } & & $\mathrm{n}$ & $\%$ & $\mathrm{n}$ & $\%$ \\
\hline Novapex & Acceptable & 27 & 90 & 30 & 100 \\
& Not acceptable & 3 & 10 & & 100 \\
Mini Apex & Acceptable & 26 & 87 & 30 & 90 \\
\multirow{2}{*}{ Propex II } & Not acceptable & 4 & 13 & & 10 \\
& Acceptable & 25 & 83 & 27 & 3 \\
\hline
\end{tabular}


Figure 1 shows the radiographic evaluation. One-sample $\mathrm{t}$ test found that the Mini Apex and Propex II measurements were significantly different from the reference value (1 mm), while those for the Novapex were similar to this ideal value $(P<0.05)$.

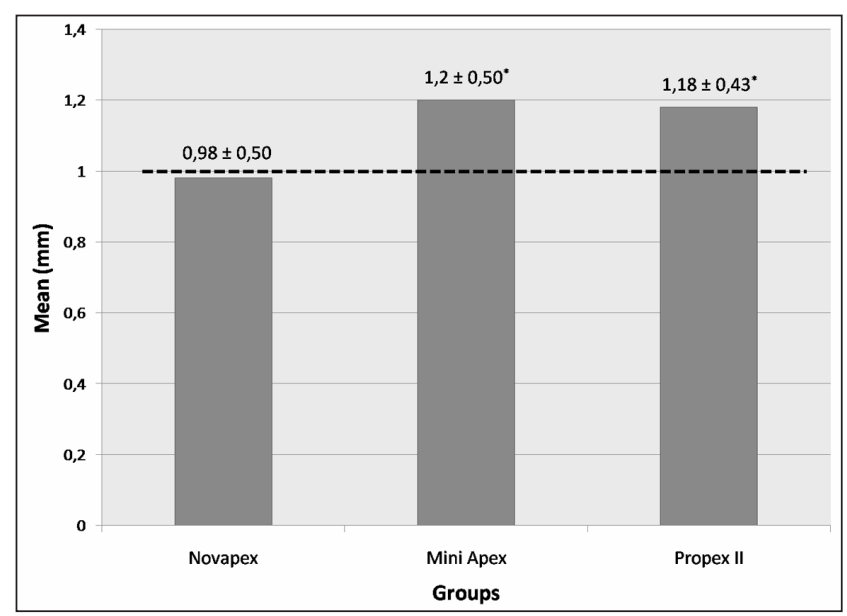

Fig. 1. Comparison between the mean values obtained for each group after preflaring and the reference value (1 mm). * Significant difference according to the one-sample t test $(P<0.05)$.

\section{Discussion}

The coronal preflaring procedure during endodontic treatment is important to remove cervical dentin interferences. It allows easier insertion of manual or rotary instruments into the apical portion of the root canals and avoids changes in the WL during the root canal preparation (19). Moreover, previous studies stated that this procedure increases the accuracy of some EALs $(12,13)$, such as the Mini Apex, which was also verify in the present study. However, it was uncertain whether preflared root canals might affect the accuracy of Novapex and Propex II because there was no evidence in the literature until now.

There have been controversial opinions about whether the EALs are able to determine the apical constriction or the apical foramen. According to Mayeda et al. (20) and Lee et al. (21), the file tips ended in the area of the major foramen regardless of the presence of the cementodentinal junction (CDJ) and then the major foramen is a better reference point to test the accuracy of the EALs. Recently, Hassanien et al. (22) verified that the CDJ and the apical constriction are two separate points, and that the width of CDJ is always greater than that of the apical constriction. When using Root ZX locator in mandibular premolars, the authors found that the measurements obtained are closer to the CDJ than to the apical constriction. Considering these findings, the present study used the major foramen as the measuring point for all three EALs, similarly to Guise et al. (23).
The manufacturers usually suggest determining the WL by using the EAL to determine the major foramen and subtracting approximately $0.5 \mathrm{~mm}$. Many practitioners believe that this procedure may still violate the apical constriction, and suggest subtracting $1 \mathrm{~mm}$, as done in this study. Guise et al. (23) found that subtracting only $0.5 \mathrm{~mm}$ would produce overextended preparations in $10 \%$ of the electronic measurements. Ultimately it is up to the practitioner to choose how to use these devices.

Several studies have been conducted in vitro and in vivo to determine the precision of EALs. Usually extracted teeth are placed in a conductive environment made of alginate $(12,24)$, agar-agar (17), or gelatin (23) for laboratory studies. In this research, a radiographic analysis was also performed. It allows the correlation between the electronic and radiographic methods, both very frequent in the clinical practice. It is important to point out that the radiographic apical vertex does not correspond to the apical foramen in several cases, but we cannot avoid some limitations inherent to the radiographic exam.

The Novapex was the most accurate EAL before and after preflaring, and it was similar to the reference value $(1 \mathrm{~mm})$ in the radiographic assessment. Other researchers have already described the acceptable accuracy of Novapex in locating the apical foramen $(14,15)$. However, D'Assunção et al. (25) found that the Novapex was not accurate in locating the apical constriction. Those authors also used single-rooted teeth in an ex vivo model, but they evaluated the apical constriction instead of the apical foramen.

The accuracy of the Novapex increased after preflaring, but there was no significant difference. On the other hand, the Mini Apex and Propex II significantly increased their accuracy after preflaring. These findings agree with those of Camargo et al. (12) who also used mandibular incisors. Ibarrola et al. (13) highlighted the importance of this procedure prior to the use of EALs in mandibular molars. It is reasonable to suggest that in curved canals the difference between the WL before and after preflaring would be even higher.

All the EALs tested showed a negative mean difference between the electronic and visual WL either before or after preflaring. On the whole, all devices had shorter electronic measurements than the visual WL. However, most of the mean differences are within the tolerance of $\pm 0.5 \mathrm{~mm}$, considered clinically acceptable in several studies $(12,17,23)$. In addition, all the EALs tested presented high percentage of acceptable cases before and after preflaring. These results suggest that all the EALs tested had an adequate accuracy.

\section{Conclusions}

Before and after preflaring, the Novapex was the most accurate at determining the correct WL. Besides, the EALs increased their accuracy after the preflaring procedure, but no significant difference was noted for the Novapex. 
1. Gordon MP, Chandler NP. Electronic apex locators. Int Endod J 2004;37:425-37.

2. Ricucci $D$, Langeland K. Apical limit of root canal instrumentation and obturation, part 2 : a histological study. Int Endod J 1998;31:394-409.

3. Kuttler Y. Microscopic investigation of root apexes. J Am Dent Assoc 1955;50:544-52.

4. Seidberg BH, Alibrandi BV, Fine H, Logue B. Clinical investigation of measuring working lengths of root canals with an electronic device and with digital-tactile sense. J Am Dent Assoc 1975;90:379-87.

5. Goldman M, Pearson AH, Darzenta N. Endodontic success: who's reading the radiograph? Oral Surg Oral Med Oral Pathol Oral Radiol Endod 1972;33:432-7.

6. Tamse A, Kattle I, Fishel D. Zygomatic arch interference with correct radiographic diagnosis in maxillary molars endodontics. Oral Surg Oral Med Oral Pathol 1980;50:563-5.

7. Sunada I. New method for measuring the length of the root canal. J Dent Res 1962;41: 375-87.

8. Kim E, Lee SJ. Electronic apex locator. Dent Clin North Am 2004;48:35-54.

9. Azabal M, Garcia-Otero D, de la Marroca JC. Accuracy of the Justy II Apex locator in determining working length in simulated horizontal and vertical fractures. Int Endod $J$ 2004;37:174-7.

10. Kaufman AY, Fuss Z, Keila S, Waxenberg S. Reliability of different electronic apex locators to detect root perforations in vitro. Int Endod J 1997;30:403-7.

11. ElAyouti A, Kimionis I, Chu AL, Lost C. Determining the apical terminus root-end resected teeth using three modern apex locators: a comparative ex vivo study. Int Endod J 2005;38:827-33.

12. Camargo EJ, Zapata RO, Medeiros PL, Bramante CM, Bernardineli N, Garcia RB, Moraes $I G$, Duarte MAH. Influence of preflaring on the accuracy of length determination with four electronic apex locators. J Endod 2009;35:1300-2.

13. Ibarrola JL, Chapman BL, Howard JH, Knowles KI, Ludlow MO. Effect of pre-flaring on Root ZX apex locators. J Endod 1999;25:625-6.

14. D'Assunção FLC, de Albuquerque DS, de Queiroz Ferreira LC. The ability of two apex locators to locate the apical foramen: an in vitro study. J Endod 2006;32:560-2.

15. Chevalier V, Arbab-Chirani R, Nicolas M, Morin V. Occurrence of no-function of two electronic apex locators: an in vivo study. Oral Surg Oral Med Oral Pathol Oral Radiol Endod 2009;108:e61-5.

16. D'Assunção FLC, de Albuquerque DS, Salazar-Silva JR, de Queiroz Ferreira LC, Bezerra PM. The accuracy of root canal measurements using the Mini Apex Locator and Root ZX II: an evaluation in vitro. Oral Surg Oral Med Oral Pathol Oral Radiol Endod 2007; 104:e50-3.

17. Briseño-Marroquín B, Frailich S, Goldberg F, Willershausen B. Influence of instrument size on the accuracy of different apex locators: an in vitro study. J Endod 2008;34:698-702.

18. Cianconi L, Angotti V, Felici R, Conte G, Mancini M. Accuracy of three electronic apex locators compared with digital radiography: an ex vivo study. J Endod 2010;36:2003-7.

19. Pécora JD, Capelli A, Guerisoli DM, Spanó JC, Estrela C. Influence of cervical preflaring on apical file size determination. Int Endod J 2005;38:430-5.

20. Mayeda DL, Simon JH, Aimar DF, Finley K. In vivo measurement accuracy in vital and necrotic canals with the Endex apex locator. J Endod 1993;19:545-8.

21. Lee SJ, Nam KG, Kim YJ. Clinical accuracy of a new apex locator with an automatic compensation circuit. J Endod 2002;28:706-9.

22. Hassanien EE, Hashem A, Chalfin H. Histomorphometric study of the root apex of mandibular premolar teeth: an attempt to correlate working length measured with electronic and radiograph methods to various anatomic positions in the apical portion of the canal. J Endod 2008;34:408-12.

23. Guise GM, Goodell GG, Imamura GM. In vitro comparison of three electronic apex locators. J Endod 2010;36:279-81.

24. Lopez FU, Barletta FB, Fontanella VRC, Grecca FS. Effect of endodontic preflaring on electronic determination of working length. Rev Odonto Cienc 2011 ;26:161-4.

25. D'Assunção FLC, de Albuquerque DS, Salazar-Silva JR, dos Santos VC, Souza JC. Ex vivo evaluation of the accuracy and coefficient of repeatability of three electronic apex locators using a simple mounting model: a preliminary report. Int Endod J 2010;43:269-74. 